\title{
Complex hereditary peripheral neuropathies caused by novel variants in mitochondrial-related nuclear genes
}

\author{
Yu Hiramatsu ${ }^{1} \cdot$ Yuji Okamoto $^{1,2}$ - Akiko Yoshimura ${ }^{1}$ Jun-Hui Yuan ${ }^{1} \cdot$ Masahiro Ando $^{1} \cdot$ Yujiro Higuchi $^{1}$. \\ Akihiro Hashiguchi ${ }^{1}$ - Eiji Matsuura ${ }^{1} \cdot$ Fumihito Nozaki $^{3} \cdot$ Tomohiro Kumada $^{4} \cdot$ Kei Murayama $^{5} \cdot$ Mikiya Suzuki $^{6}$. \\ Yuki Yamamoto ${ }^{7}$. Naoko Matsui ${ }^{7} \cdot$ Yoshimichi Miyazaki ${ }^{8} \cdot$ Masamitsu Yamaguchi ${ }^{9} \cdot$ Youji Suzuki ${ }^{10}$. Jun Mitsui ${ }^{11}$. \\ Hiroyuki Ishiura $^{11}$ - Masaki Tanaka ${ }^{12}$. Shinichi Morishita ${ }^{13} \cdot$ Ichizo Nishino $^{14} \cdot$ Shoji Tsuji $^{11,12} \cdot$ Hiroshi Takashima $^{1}$ (D)
}

Received: 18 January 2022 / Revised: 5 February 2022 / Accepted: 11 February 2022 / Published online: 2 March 2022

(c) The Author(s) 2022

\begin{abstract}
Mitochondrial disorders are a group of clinically and genetically heterogeneous multisystem disorders and peripheral neuropathy is frequently described in the context of mutations in mitochondrial-related nuclear genes. This study aimed to identify the causative mutations in mitochondrial-related nuclear genes in suspected hereditary peripheral neuropathy patients. We enrolled a large Japanese cohort of clinically suspected hereditary peripheral neuropathy patients who were mutation negative in the prescreening of the known Charcot-Marie-Tooth disease-causing genes. We performed whole-exome sequencing on 247 patients with autosomal recessive or sporadic inheritance for further analysis of 167 mitochondrial-related nuclear genes. We detected novel bi-allelic likely pathogenic/pathogenic variants in four patients, from four mitochondrial-related nuclear genes: pyruvate dehydrogenase beta-polypeptide $(P D H B)$, mitochondrial poly(A) polymerase (MTPAP), hydroxyacyl-CoA dehydrogenase/3-ketoacyl-CoA thiolase/enoyl-CoA hydratase, beta subunit (HADHB), and succinate-CoA ligase ADP-forming beta subunit (SUCLA2). All these patients showed sensory and motor axonal polyneuropathy, combined with central nervous system or multisystem involvements. The pathological analysis of skeletal muscles revealed mild neurogenic changes without significant mitochondrial abnormalities. Targeted screening of mitochondria-related nuclear genes should be considered for patients with complex hereditary axonal polyneuropathy, accompanied by central nervous system dysfunctions, or with unexplainable multisystem disorders.
\end{abstract}

Keywords Peripheral neuropathy $\cdot$ Whole-exome sequencing $\cdot$ Nuclear genes $\cdot$ Mitochondrial disease

Hiroshi Takashima

thiroshi@m3.kufm.kagoshima-u.ac.jp

1 Department of Neurology and Geriatrics, Kagoshima University Graduate School of Medical and Dental Sciences, 8-35-1 Sakuragaoka, Kagoshima City, Kagoshima 890-8520, Japan

2 Department of Physical Therapy, School of Health Sciences, Faculty of Medicine, Kagoshima University, Kagoshima, Japan

3 Department of Pediatrics, Shiga Medical Center for Children, Shiga, Japan

4 Kumada Kids Family Clinic, Shiga, Japan

5 Department of Metabolism, Chiba Children's Hospital, Chiba, Japan

6 Department of Neurology, National Hospital Organization Higashisaitama Hospital, Saitama, Japan

7 Department of Neurology, Tokushima University Graduate School of Medicine, Tokushima, Japan
8 Department of Neurology, Hyogo Prefectural Awaji Medical Center, Hyogo, Japan

9 Kansai Gakken Laboratory, Kankyo Eisei Yakuhin Co. Ltd., Seika-cho, Kyoto, Japan

10 Department of Neurology, Yaizu City Hospital, Shizuoka, Japan

11 Department of Neurology, Graduate School of Medicine, The University of Tokyo, Tokyo, Japan

12 Institute of Medical Genomics, International University of Health and Welfare, Chiba, Japan

13 Department of Computational Biology and Medical Sciences, Graduate School of Frontier Sciences, The University of Tokyo, Chiba, Japan

14 Department of Neuromuscular Research, National Center of Neurology and Psychiatry (NCNP), National Institute of Neuroscience, Tokyo, Japan 


\section{Introduction}

Peripheral neuropathy has various causes, one of which is mitochondrial abnormalities. Mitochondrial-related nuclear genes, such as MFN2 and GDAP1 that are involved in mitochondrial dynamics, are major causes of Charcot-Marie-Tooth disease (CMT) [1, 2], the most common subtype of hereditary peripheral neuropathy. In MFN2, known as CMT2A and HMSN6A, phenotypes may cause optic atrophy, and in GDAP1, they may cause vocal cord paresis [2] so the spectrum of CMT has considerably broadened and multisystem involvement is frequently observed similar to other disorders caused by mutations in mitochondrial DNA (mtDNA) or mitochondria-related nuclear genes. Moreover, mitochondrial disorders associated with defects in mitochondrial DNA (mtDNA) maintenance and replication or defects in the respiratory chain complex are often associated with peripheral neuropathy [2]. Although the severity of these disorders is usually mild or subclinical, peripheral neuropathy can be severe and might be the main feature of a mitochondrial disorder [3]. Given that $>1100$ mitochondrialrelated nuclear genes have been identified and $>240$ nuclear genes cause mitochondrial disorders [4, 5]; we speculate that more mutations in mitochondrial-related nuclear genes cause patients to manifest the CMT-like phenotype. In this study, through whole-exome sequencing (WES) data, we examined a large cohort of Japanese patients with clinically suspected hereditary peripheral neuropathy patients to determine the presence of variants in a panel of mitochondrial-related nuclear genes.

\section{Materials and methods}

\section{Patient selection and extraction of genomic DNA}

After preliminary exclusion of the PMP22 duplication or deletion mutation, using fluorescence in situ hybridization or multiplex ligation probe amplification, we enrolled a nationwide cohort of 854 Japanese patients clinically suspected with pure or complex hereditary peripheral neuropathy, between April 2007 and July 2014. All of their clinical information, electrophysiological and radiological records, and pathological findings, were provided by local neurologists or pediatricians. The protocol was reviewed and approved by the Institutional Review Board of Kagoshima University (Kagoshima, Japan). All patients and family members provided written informed consent to participate in this study. The study conforms with the World Medical Association Declaration of Helsinki published on the website of the Journal of American Medical Association.
Genomic DNA was isolated from peripheral blood leukocytes, using the Qiagen Puregene Core Kit C (Qiagen, Valencia, CA, USA), or from the saliva, using the Oragene DNA self-collection kit (DNA Genotek, Ottawa, ON, Canada), according to the manufacturer's protocol.

\section{Gene panel screening and WES}

All 854 DNA samples were processed on 1 of the 2 types of CMT-related gene panel screening platforms. Between April 2007 and April 2012, 417 cases were screened using a customized MyGeneChip ${ }^{\circledR}$ CustomSeq ${ }^{\circledR}$ Custom Resequencing Array (Affymetrix, Inc., Santa Clara, CA, USA), targeting 28 genes known to cause CMT or related diseases following a protocol described previously [6]. Between May 2012 and July 2014, we used the Illumina MiSeq next-generation sequencing platform to screen 437 patients for 40 known CMT disease-causing and 20 candidate genes [7]. After target resequencing, we used WES to further analyze 399 mutation-negative patients, including 247 patients with autosomal recessive (AR) or sporadic inheritance.

We used a SureSelect v4 + UTRs or v5 + UTRs kit, then sequenced on Illumina HiSeq $2000 \circledR$ (Illumina, San Diego, CA, USA). WES data were aligned to the human reference genome (NCBI37/hg19) with Burrows-Wheeler Aligner [8], and variant call was performed using SAM tool [9], The CLC Genomic Workbench software program (Qiagen, Hilden, Germany) and an in-house R script were applied for variant annotation and filtering.

\section{Variant identification and segregation analysis}

We concentrated on the WES variants in a list of 167 known mitochondrial-related nuclear genes, which was modified from the Baylor Genetics (https://www.bcm.edu/research/ medical-genetics-labs/) BCM-MitomeNGS panel (Supplementary Table 1). Sanger sequencing was applied to validate the suspected pathogenic variants. We carried out segregation studies for other family members whenever available. All variants were checked against the single nucleotide polymorphism database (dbSNP: http://www.ncbi.nlm.nih. gov/SNP/), the gnomAD browser (https://gnomad.broadinsti tute.org) as a global control database, the Human Genetic Variation Database (http://www.hgvd.genome.med.kyoto-u. ac.jp) and Japanese Multi Omics Reference Panel (jMorp 8.5 K: https://jmorp.megabank.tohoku.ac.jp/ijgvd/) as Japanese databases, and the in-house database to assess whether they were normal variants. Moreover, to perform in silico analysis, we used four prediction algorithms: PolyPhen-2 (http://genetics.bwh.harvard.educut/pph2, cut-off $>0.9$ ), SIFT (http://sift.jcvi.org, cut-off <0.05), PROVEAN (http:// provean.jcvi.org/index.php, cut-off $<-2.5$ ), Mutation Taster (http://mutationtaster.org, scores ranging between 0 and 215, 
variants suspected of pathogenicity are classified as "disease-causing" and variants suspected of less pathogenicity are classified as "polymorphisms"). We interpreted variants according to the American College of Medical Genetics and Genomics and the Association for Molecular Pathology (ACMG/AMP) standards and guidelines [10].

\section{RNA extraction and reverse-transcription polymerase chain reaction (RT-PCR)}

Total RNA was extracted from whole blood of Patient 4 using the PAXgene Blood RNA Kit (Qiagen). Subsequently, complementary DNA (cDNA) was produced with a highcapacity cDNA reverse-transcription kit (Applied Biosystems, Carlsbad, CA, USA) according to the manufacturer's instructions. To analyze the effect of the splice site variant in the succinate-CoA ligase ADP-forming beta subunit (SUCLA2) gene, we amplified SUCLA2 cDNA using the following primer pairs:

- Forward primer located in exon 4: 5'-GGAAGTTCACAT GGTGGTGTC-3'

- Reverse primer located in exon 7: 5'-TGAGATTTGCCT TAGCAGCA-3'

\section{Clinical studies}

Clinical findings and laboratory data, nerve conduction studies (NCS), and image examinations were based on the currently available information for all patients. The primary physician performed histological investigations of the sural nerve biopsy in Patient 1 as well as skeletal muscle biopsies in Patients 3 and 4, after obtaining informed consent. In Patient 4 , respiratory chain enzyme activities in the skeletal muscle homogenate were also assayed as described earlier [11].

\section{Results}

From WES data of 247 CMT patients with AR or sporadic inheritance, we concentrated all uncommon variants (allele frequency $<0.05$ ) in the mitochondria-related 167 nuclear gene panel. Therein, bi-allelic variants were identified in four patients, from four distinct genes. These genes were pyruvate dehydrogenase, beta-polypeptide $(P D H B)$, mitochondrial poly(A) polymerase (MTPAP), hydroxyacylCoA dehydrogenase/3-ketoacyl-CoA thiolase/enoyl-CoA hydratase, beta subunit (HADHB), and SUCLA2. These variants comprise c.880G $>$ A (p.G294R) homozygous variants in $P D H B$ (Fig. 1a), c.833G $>$ T (p.R278I) and c.1531C $>\mathrm{T}$ (p.Q511*) compound heterozygous variants in MTPAP (Fig. 1b), c.1192 T >C (p.F398L) homozygous variants in $H A D H B$ (Fig. 1c), and c.664-1G > A and c.1,300delG (p.D434fs) compound heterozygous variants in SUCLA2 (Fig. 1d). All the missense variants were novel and located at a highly conserved amino acid residues (Fig. 1e-h), and most variants were located in each protein domain region (Fig. 1i-1). All variants were absent in the control database and predicted to be damaging or deleterious during in silico analysis; the in silico analysis results as well as the classification by ACMG standards and guidelines are shown in Supplementary Table 2 . The genetic and clinical presentations of the patients are summarized in Table 1.

Segregation analyses were performed for the parents of all four patients, except Patient 3, whose parents were deceased. The same genotype was detected in an affected elder brother of Patient 2 (Fig. 2).

\section{Patient 1 [PDHB c.880G > A (p.G294R)]}

This patient was a woman in her $30 \mathrm{~s}$ who was born weighing $2400 \mathrm{~g}$. By 2 years of age, she had a ventricular septal defect and seizures four times. She began walking at 1 year and 6 months but had gait disturbance. The surgery of the strabismus was performed at age 4 and of the ileus at age 15. Gait disturbance progressed, and sural nerve biopsy was performed at age 25 . A decrease in the density of large myelinated fibers with thin small myelinated clusters was revealed by nerve analysis (Fig. 3a). Simultaneously, adjustment disorder associated with mild-to-moderate intellectual disability was observed. Cerebral atrophy with no white matter lesions was shown by brain magnetic resonance imaging (MRI) (Fig. 3b). Clinically, the patient had weakness and atrophy of the distal limb muscles, pes cavus, and hallux valgus. Disturbance of the leg vibration sense and decreased tendon reflexes were also noted. Axonal polyneuropathy was revealed by NCS (Table 1).

\section{Patient 2 [MTPAP c.833G > T(p.R278I) c.1531C > T (p.Q511*)]}

This male patient in his $30 \mathrm{~s}$ who had gait disturbance at the age of 1 year and 6 months. At 28 years, scoliosis, equinus foot, and paresthesia were present, and he could not walk. Sensory-dominant axonal polyneuropathy was revealed by NCS (Table 1), and he had skin acne through the lumbar region from the head. Low levels of vitamin $B_{12}(70 \mathrm{ng} /$ $\mathrm{mL}$; normal: $180-914 \mathrm{ng} / \mathrm{mL})$ and folate $(1.3 \mathrm{ng} / \mathrm{mL}$; nor$\mathrm{mal}:>3 \mathrm{ng} / \mathrm{mL}$ ) were revealed in laboratory investigations, but the intrinsic factor antibody and gastric parietal cell antibody were negative. An upper gastrointestinal endoscopy showed only atrophic gastritis. Patchy T2 hyperintensities in the white matter of the temporal and occipital lobes (Fig. 3c) were revealed by brain MRI. 


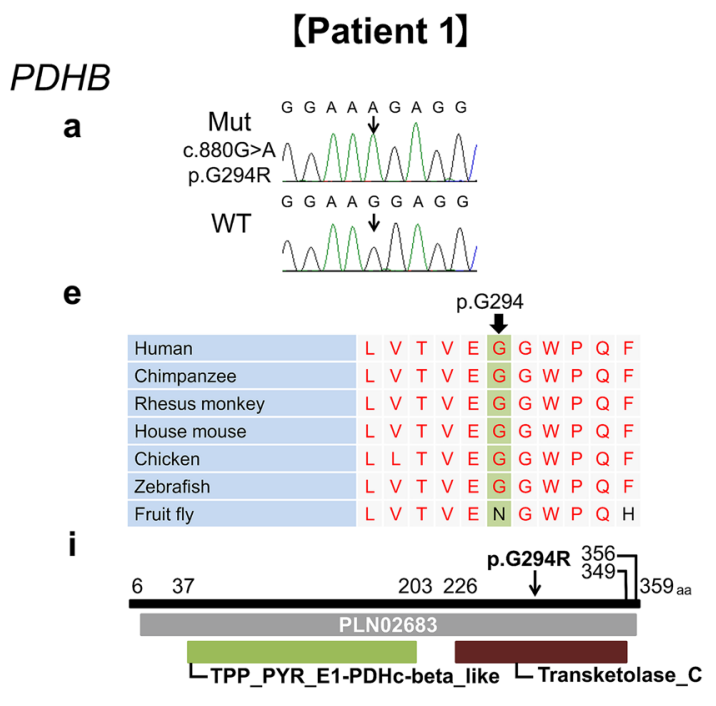

\section{【Patient 3】}

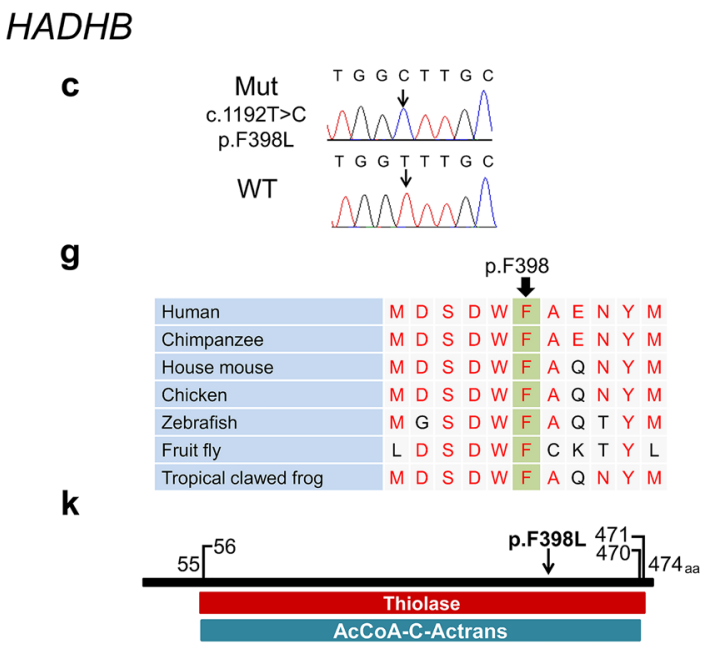

Fig. 1 Localization and conservation of mitochondrial-related nuclear gene variants. a-d Sequencing chromatograms of c.880G $>$ A (p.G294R) mutation in $P D H B$ gene (a), c.833G $>$ T (p.R278I) and c.1531C $>\mathrm{T}\left(\mathrm{p} . \mathrm{Q} 511^{*}\right)$ in MTPAP gene (b), c.1192 T>C (p.F398L) in $H A D H B$ gene (c), and c.664-1G $>$ A and c.1300delG (p.D434Mfs*8) in SUCLA2 gene (d). The patient number is noted above. Arrows indicate mutation sites. $\mathbf{e}-\mathbf{h}$ Conservation analysis of amino acid sequences on the mutation sites in PDHB (e), MTPAP (f),

During elementary school, his elder brother, who had the same MTPAP variants, also had gait disturbance, amblyopia, and scoliosis, and he began using a wheelchair at 38 years of age. We observed hypoesthesia and optic atrophy, and axonal polyneuropathy was revealed by NCS. His vitamin $B_{12}$ levels were low, and despite supplementation, the symptoms worsened.

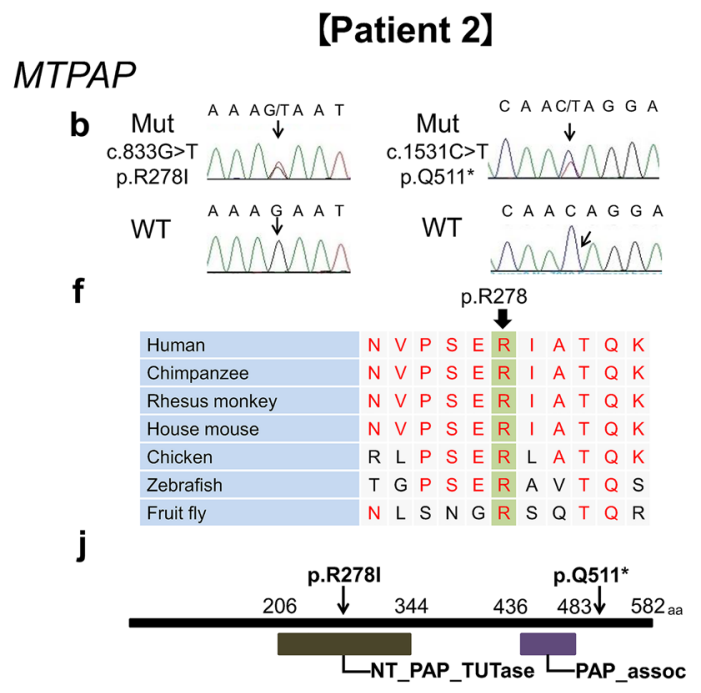

【Patient 4】

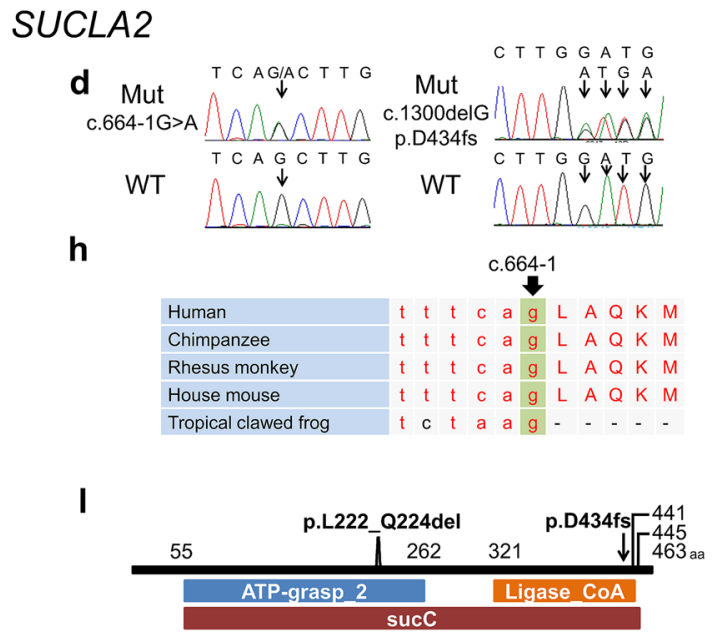

and $H A D H B$ (g) genes and canonical GT-AG nucleotides (c.664-1 g) of the splice acceptor junctions in the SUCLA2 gene (h). These mutation sites were highly conserved. i-l Predicted positions of amino acids affected and domain structure of PDHB protein (i), MTPAP protein (j), HADHB protein (k), and SUCLA2 protein (l) based on an NCBI conserved domain search (http://www.ncbi.nlm.nih.gov/Struc ture/cdd/wrpsb.cgi). Arrows indicate mutation sites. aa amino acids, Mut mutant, $W T$ wild type

\section{Patient 3 [HADHB c.1192 T > C (p.F398L)]}

Details about this case were previously established [12]. A man in his $50 \mathrm{~s}$ had languor of the lower extremity and brown urine after exercise at the age of 10 . For a while, symptoms improved but recurred at age 45 , and gait disturbance progressed. At age 55, deep tendon reflexes were 
Table 1 Genetic and clinical features of four patients with mitochondrial-related nuclear gene variants

\begin{tabular}{|c|c|c|c|c|c|c|c|c|}
\hline \multirow{2}{*}{$\begin{array}{l}\text { Patient No } \\
\text { Gene symbol }\end{array}$} & \multicolumn{2}{|l|}{ Patient 1} & \multicolumn{2}{|l|}{ Patient 2} & \multicolumn{2}{|l|}{ Patient 3} & \multicolumn{2}{|l|}{ Patient 4} \\
\hline & \multicolumn{2}{|l|}{$P D H B$} & \multicolumn{2}{|l|}{ MTPAP } & \multicolumn{2}{|l|}{$H A D H B$} & \multicolumn{2}{|l|}{ SUCLA2 } \\
\hline Mutation & \multicolumn{2}{|l|}{$\begin{array}{l}\text { c. } 880 G>A \\
(\text { p.G294R) }\end{array}$} & $\begin{array}{l}\text { c. } 833 \mathrm{G}>\mathrm{T} \\
(\mathrm{p} \cdot \mathrm{R} 278 \mathrm{I})\end{array}$ & $\begin{array}{l}\text { c. } 1531 \mathrm{C}>\mathrm{T} \\
\left(\mathrm{p} . \mathrm{Q} 511^{*}\right)\end{array}$ & \multicolumn{2}{|l|}{$\begin{array}{l}\text { c. } 1192 \mathrm{~T}>\mathrm{C} \\
(\mathrm{p} . \mathrm{F} 398 \mathrm{~L})\end{array}$} & $\begin{array}{l}\text { c.1300delG } \\
\text { (p.D434Mfs*8) }\end{array}$ & $\begin{array}{l}\text { c.664-1G >A } \\
\text { (p.L222_- } \\
\text { Q224del) }\end{array}$ \\
\hline Genotype & \multicolumn{2}{|l|}{ Homo } & \multicolumn{2}{|l|}{ C Hetero } & \multicolumn{2}{|l|}{ Homo } & \multicolumn{2}{|l|}{ C Hetero } \\
\hline $\begin{array}{l}\text { Age at the most recent } \\
\text { exam (years)/Sex }\end{array}$ & \multicolumn{2}{|l|}{$37 / \mathrm{F}$} & \multicolumn{2}{|l|}{$37 / \mathrm{M}$} & \multicolumn{2}{|l|}{$56 / \mathrm{M}$} & \multicolumn{2}{|l|}{$4 / \mathrm{F}$} \\
\hline Onset & \multicolumn{2}{|l|}{0 years } & \multicolumn{2}{|l|}{1 years } & \multicolumn{2}{|l|}{10 years } & \multicolumn{2}{|l|}{3 months } \\
\hline Consanguinity & \multicolumn{2}{|l|}{ No } & \multicolumn{2}{|l|}{ No } & \multicolumn{2}{|l|}{ No } & \multicolumn{2}{|l|}{ No } \\
\hline Segregation & \multicolumn{2}{|l|}{ Yes } & \multicolumn{2}{|l|}{ Yes } & \multicolumn{2}{|l|}{ NA } & \multicolumn{2}{|l|}{ Yes } \\
\hline Initial symptom & \multicolumn{2}{|l|}{ Seizure } & \multicolumn{2}{|c|}{ Gait disturbance } & \multicolumn{2}{|c|}{ Languor of lower extremity } & $\begin{array}{r}\text { Hypotonia, Ptos } \\
\text { Scaphocephal }\end{array}$ & afness, \\
\hline MMT $^{\mathrm{a}}$ & 2 & & 1 & & 3 & & 3 & \\
\hline Sensory disturbance & Yes & & Yes & & Yes & & No & \\
\hline DTRs & All absent bil & & All absent bil & & All absent bilate & & All absent bilate & \\
\hline NCS & & & & & & & & \\
\hline dCMAP (mV) & Median 4.2 & Tibial 2.53 & Median 18.9 & Tibial 1.98 & Median 0.41 & Tibial 1.49 & Median 2.66 & Tibial 0.96 \\
\hline $\mathrm{MCV}(\mathrm{m} / \mathrm{s})$ & Median 46.4 & Tibial 43.9 & Median 59.7 & Tibial 53.7 & Median 54.5 & Tibial 39.1 & Median 61.6 & Tibial 31.8 \\
\hline $\operatorname{SNAP}(\mu \mathrm{V})$ & Median 4.2 & Sural 1.66 & Median ND & Sural ND & Median 3.62 & Sural ND & Median 29.1 & Sural 8.4 \\
\hline $\mathrm{SCV}(\mathrm{m} / \mathrm{s})$ & Median 53.8 & Sural 45.6 & Median ND & Sural ND & Median 48.4 & Sural ND & Median 54.1 & Sural 54.3 \\
\hline Other findings & $\begin{array}{l}\text { Pes cavus } \\
\text { Hallux valgus } \\
\quad \text { infant } \\
\text { Intellectual di } \\
\text { Strabismus } \\
\text { VSD } \\
\text { Ileus }\end{array}$ & $\begin{array}{l}\text { l-for-date } \\
\text { ty }\end{array}$ & $\begin{array}{l}\text { Equinus foot } \\
\text { Scoliosis } \\
\text { Skin acne } \\
\text { Vitamin } B_{12}\end{array}$ & late deficiency & $\begin{array}{l}\text { Pes cavus } \\
\text { Hammer toes } \\
\text { Brown urine } \\
\text { Rhabdomyolysis }\end{array}$ & & $\begin{array}{l}\text { Encephalopathy } \\
\text { Intellectual disa } \\
\text { Dystonia } \\
\text { Ophthalmoplegi } \\
\text { Scoliosis } \\
\text { Periodic vomitir } \\
\text { Lactic acidosis } \\
\text { Methylmalonic }\end{array}$ & \\
\hline
\end{tabular}

C Hetero compound heterozygous, $d C M A P$ distal compound muscle action potential, DTRs deep tendon reflexes, Homo homozygous, $M C V$ motor conduction velocity, MMT manual muscle testing, $N A$ not available, $N C S$ nerve conduction study, $N D$ not detected (evoked), $S C V$ sensory conduction velocity, SNAP sensory nerve action potential, VSD ventricular septal defect

${ }^{\text {a }}$ Scores indicating manual muscle testing (MMT) grade in the distal lower limbs

absent, and muscle weakness and atrophy in his distal lower limbs were present. His senses of vibration and position were deeply disturbed, and sensory ataxia was present. Axonal sensorimotor polyneuropathy was shown by NCS (Table 1) and normal creatine kinase levels by laboratory investigations. After gene analysis, he suffered from recurrent rhabdomyolysis. Neurogenic changes, such as marked fiber-type grouping were revealed by open muscle biopsy (Fig. 3d), but there was no mitochondrial abnormality. His 3-hydroxy-tetradecanoyl carnitine $\left(\mathrm{C}_{14}-\mathrm{OH}\right)$ level was slightly increased $(0.06 \mathrm{nmol} / \mathrm{mL}$; normal: $<0.05 \mathrm{nmol} / \mathrm{mL})$.

\section{Patient 4 [SUCLA2 c.1300delG (p.D434Mfs*8) c.664-1G > A (p.L222_Q224del)]}

Details about this case were previously established [13]. This infant girl was born weighing 2,450 g. At 3 months, ptosis, deafness, scaphocephaly, and axial hypotonia were observed. At 7 months, profound intellectual disability was noted. At 1 year, she developed dysphagia, and tube feeding was started. At 2 years, gastroesophageal reflux and scoliosis were observed accompanied by cyclic vomiting and hypercapnia during sleep. NCS showed that axonal polyneuropathy predominantly affected the motor nerves (Table 1). Laboratory tests showed increased levels of mild methylmalonic aciduria $(34.1 \mu \mathrm{g} / \mathrm{mg}$ creatinine; normal: $<10 \mu \mathrm{g} / \mathrm{mg}$ creatinine), blood lactate $(58.5 \mathrm{mg} /$ $\mathrm{dL}$; normal: $4-17 \mathrm{mg} / \mathrm{dL})$, and pyruvate $(2.17 \mathrm{mg} / \mathrm{dL}$; normal: $0.3-0.9 \mathrm{mg} / \mathrm{dL}$ ), and cerebrospinal fluid lactate and pyruvate levels were $27.9 \mathrm{mg} / \mathrm{dL}$ and $1.81 \mathrm{mg} / \mathrm{dL}$, respectively. Brain MRI revealed cerebral atrophy and $\mathrm{T} 2$ hyperintensities in the bilateral putamen and caudate nuclei (Fig. 3e) and a lactate peak in magnetic resonance spectroscopy (Fig. 3f). Therefore, Leigh syndrome was suspected; however, there was no known mitochondrial DNA mutation in peripheral blood lymphocytes. Open muscle biopsy showed a neurogenic change in the fibertype grouping (Fig. 3g), but no insufficient cytochrome $c$ oxidase activity, ragged red fibers, or increased staining for succinate dehydrogenase were observed. Hence, she was tentatively diagnosed with CMT2 or other complex hereditary peripheral neuropathy. 
Fig. 2 Pedigrees of families with novel mitochondrialrelated nuclear gene variants. Genotypes of the variants are indicated at the bottom of the pedigree for each examined individual. Arrows and asterisks indicate the proband of each family and individual whose genome was applied for Sanger sequencing. del deletion, $W T$ wild type
【Patient 1】

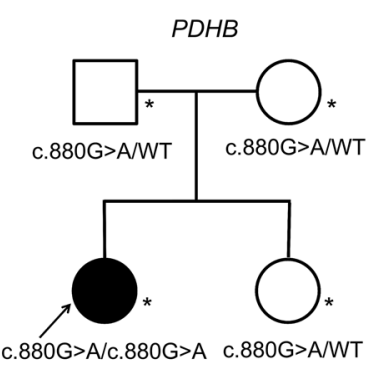

[Patient 2】

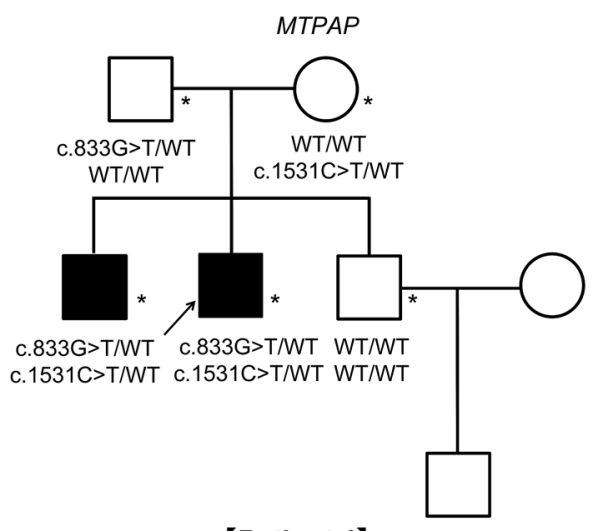

【Patient 4】

I

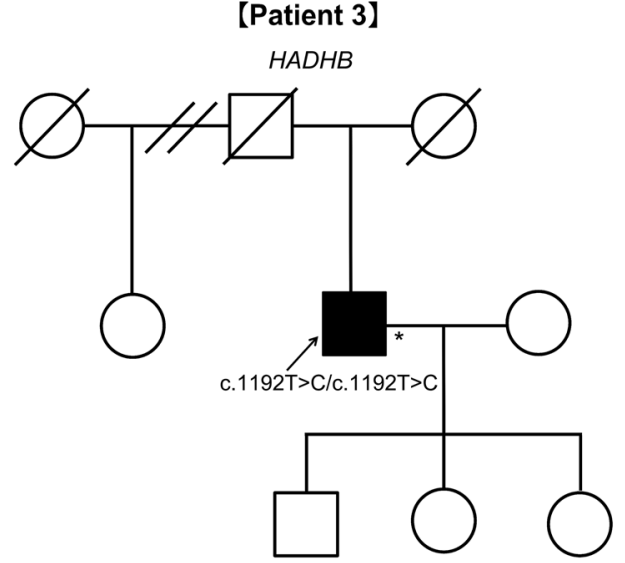
SUCLA2

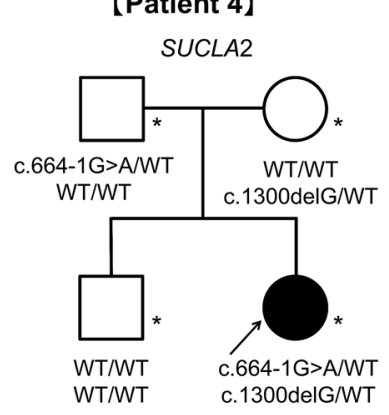

After the gene analysis, the muscle respiratory chain enzyme activities showed deficiencies in complexes I (45\%) and IV (43\%), whereas complex II (the only complex that does not contain mtDNA-encoded proteins) was normal (105\%; each activity was expressed as the citrate synthase ratio).

Regarding heterozygous splice acceptor site variant (c.664-1G>A) in intron 5, we detected two RT-PCR products comprising a wild-type band and a smaller band at $370 \mathrm{bp}$ (Fig. 4a). Sanger sequencing of the RT-PCR product revealed 9 bp heterozygous deletion (Fig. 4b), leading to the in-frame deletion of three amino acids in exon 6 of SUCLA2 (p.L222_Q224del; Fig. 4c).

\section{Discussion}

Using WES, we performed further genetic analysis targeting 167 mitochondrial-related nuclear genes among a group of patients with clinically suspected with pure or complex hereditary peripheral neuropathy. In four patients, we identified four disease-causing genes, of which variants in $P D H B$, $M T P A P$, and SUCLA2 have been reported not as a cause of CMT but of other diseases associated with symptomatic or subclinical peripheral neuropathy [14-16]. Although recessive mutations in $H A D H B$ have been assumed to be associated with axonal CMT, no pathophysiological mechanism was elucidated $[17,18]$. We indicated the pathological significance of the $P D H B$ and $H A D H B$ genes using Drosophila neuron-specific knockdown models in a previous study [19, 20]. Although all four patients presented with various phenotypes, motor and sensory axonal neuropathy was the major clinical feature.

The pyruvate dehydrogenase alpha (PDHA) and $P D H B$ encode pyruvate dehydrogenase, a component enzyme of the pyruvate dehydrogenase multienzyme complex in mitochondria [21]. Recessive $P D H B$ mutation causes pyruvate dehydrogenase complex (PDC) deficiencies with severe clinical consequences that primarily affect the nervous system, such as developmental delay, seizures, central hypotonia, ataxia, peripheral neuropathy, microcephaly, congenital brain malformations, and degenerative changes, such as Leigh syndrome [14, 21, 22]. Given that cases of thiamine-sensitive PDC deficiency have been reported and a ketogenic diet may alleviate the symptoms [21], it is important to diagnose this disease. In $3-21 \%$ of patients, peripheral neuropathy has been found to be linked to PDC deficiencies [21], whereas progressive peripheral neuropathy in adult patients has been linked only to mutations in PDHA1 [22]. In Patient 1, in addition to peripheral neuropathy, central nervous system 


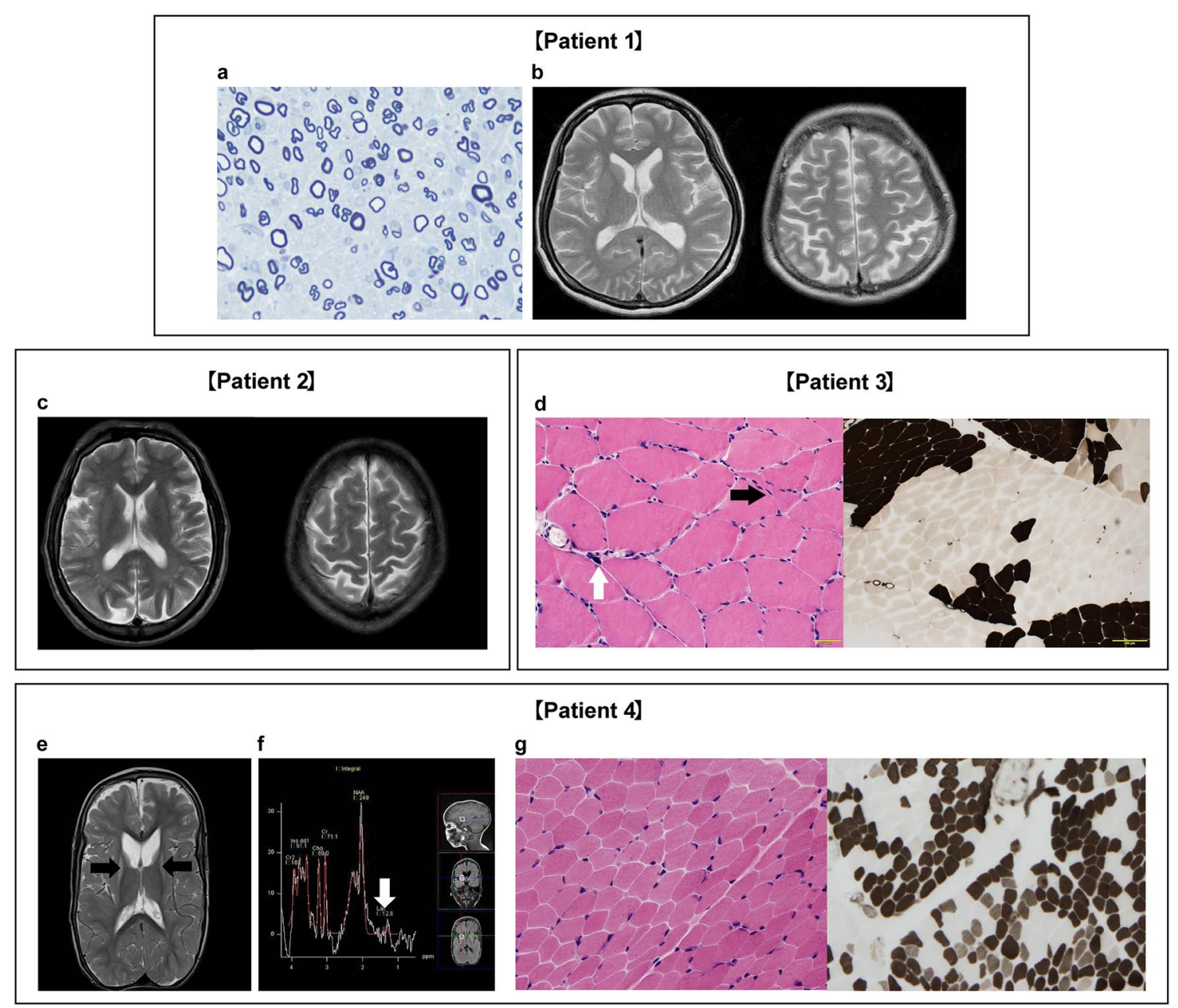

Fig. 3 Brain imaging, peripheral nerve analysis, and analysis of skeletal muscle. a Toluidine blue staining of a sural nerve in Patient 1. Densities of large myelinated fibers are decreased, and fibers with thin myelin are occasionally noted. b Axial T2 images showing cerebral atrophy but no white matter lesions in Patient 1. c Axial T2 images showing cerebral atrophy, patchy areas, and white matter lesions in the temporal and occipital lobes in Patient 2. d Muscle biopsy showing mild variation in fiber size with a small angular fiber (black arrow) and pyknotic nuclear clump (white arrow) (hema-

involvement was suggested by multiple manifestations, comprising seizures, intellectual disability, and cerebral atrophy in brain MRI. The G294R variant is located at the transketolase coding region of the C-terminal domain of the PDHB protein (Fig. 1i) and is close to the previously reported mutations of PDC deficiencies [14].

MTPAP gene encodes the mitochondrial polyadenylation polymerase, involved in DNA maintenance and repair [23]. Recessive mutation in MTPAP would result in delayed DNA repair, elevation of the level of DNA double-strand breaks, reactive oxygen species, and cell death after irradiation, leading to spastic ataxia and optic atrophy or encephalopathy. A previous case report described progressive lower toxylin and eosin staining) and marked fiber-type grouping (ATPase pH 10.6 staining) in Patient 3. e Axial T2 images showing scaphocephaly, cerebral atrophy, and hyperintensities in the bilateral putamen and caudate nuclei (black arrows) in Patient 4. f Pathological lactate accumulation was detected by magnetic resonance spectroscopy at short echo time ( $\mathrm{TE}=30 \mathrm{~ms}$ ) in this area (white arrow). $\mathbf{g}$ Muscle biopsy showing mild variation in fiber size (hematoxylin and eosin staining) and fiber-type grouping (ATPase $\mathrm{pH} 10.4$ staining) in Patient 4

motor neuron involvement due to MTPAP mutation [15] but progressive peripheral neuropathy, especially sensory nerves, without pyramidal signs, as observed in family 2 , has not previously been described.

Importantly, low levels of vitamin $\mathrm{B}_{12}$ and folate, as found in Patient 2 and his brother, might also cause peripheral neuropathy. Folate and vitamin $\mathrm{B}_{12}$, especially methylcobalamin, are coenzymes for cytosolic methionine synthase involved in vital cellular processes, such as methylation and DNA synthesis [24, 25]. Bi-allelic mutations of MTPAP would elevate both DNA double-strand breaks and cell death, whereas over-consumption of vitamin $B_{12}$ and folate for DNA synthesis could cause deficiencies of 
Fig. 4 RNA analysis of SUCLA2. a Agarose gel electrophoresis of cDNA fragments obtained from the RT-PCR of Patient 4. Patient 4 had the expected $379 \mathrm{bp}$ band and an additional $370 \mathrm{bp}$ band, which is the result of the deletion of exon 6 in one allele. $\mathbf{b}, \mathbf{c}$ Sequence chromatogram of the RT-PCR product from Patient 4 showing heterozygote $9 \mathrm{bp}$ deletion in exon $6 . b p$ base pairs, $N C$ normal control a

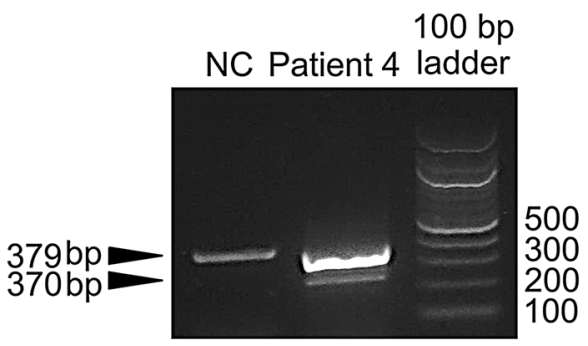

b

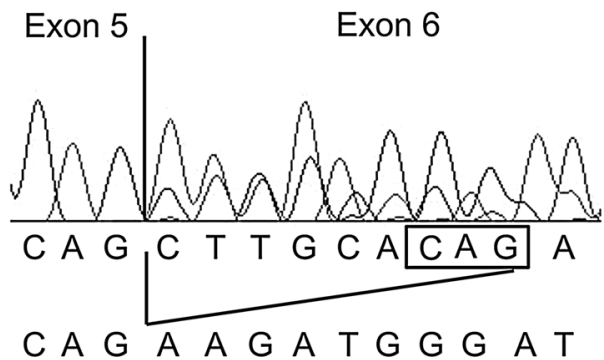

C

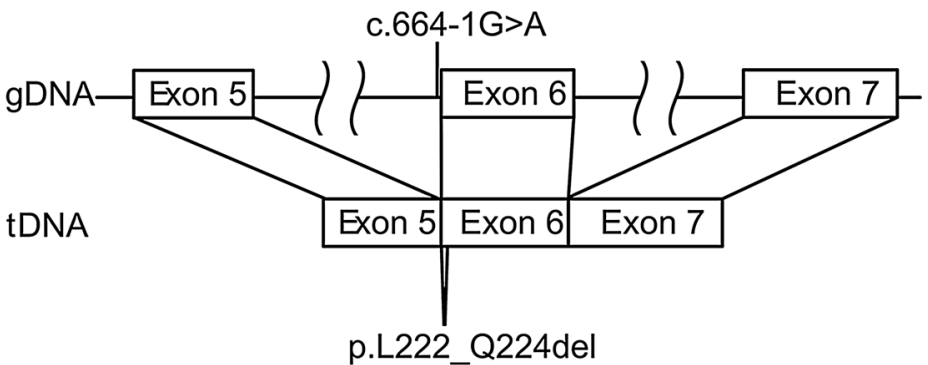

these substances. Despite the normalization of vitamin $\mathrm{B}_{12}$ and folate levels by supplementary treatment, their symptoms progressed, suggesting other contributive reasons. In family 2, segregation analysis confirmed that p.R278I and p.Q511* of MTPAP are compound heterozygotes, which would affect both DNA strands, thereby influencing the MTPAP protein function. The p.R279I variant is located in the nucleotidyltransferase (NT) domain of poly(A) polymerases and terminal uridylyl transferases (Fig. 1j); no mutation is reported in this domain. Because the p.Q511* variant is located in the last exon, and loss-of-function has not been a recognized mechanism in MTPAP-related disease, this variant was classified as "strong," as per the ACMG standards and guidelines. Further investigations are needed to clarify the role of vitamin $\mathrm{B}_{12}$ and folate in the pathogenesis of $M T P A P$-related peripheral neuropathy.

The alpha and beta subunits of the mitochondrial trifunctional protein (MTP) are encoded by the $H A D H A$ and $H A D H B$ genes [26]. These subunits catalyze three steps in the beta-oxidation of fatty acids, including the long-chain 3-hydroxyacyl-CoA dehydrogenase step. Recessive $H A D H B$ mutation results in the dysfunction of the beta-oxidation of fatty acids, leading to MTP deficiency, characterized in a severe heterogeneous syndrome, such as cardiomyopathy, recurrent Leigh-like encephalopathy, hepatopathy, and neonatal or unexpected infant death [27]. In contrast, the milder form is characterized by later-onset progressive axonal peripheral neuropathy (approximately 50-80\%) and myopathy with or without episodic myoglobinuria $[17,26]$. Phenylalanine 398 is located in the thiolase, C-terminal domain of HADHB protein (Fig. 1k), and is close to known mutations linked to the milder form [26]. After the genetic diagnosis, Patient 3 experienced recurrent episodes of brown urine after exercise and rhabdomyolysis, and his $\mathrm{C}_{14}-\mathrm{OH}$ level increased slightly; all these characteristic phenotypes were considered supportive evidence to his diagnosis. As described for Patient 3, peripheral neuropathy may be the main symptom in patients with $H A D H B$ mutations, or at least in certain stages of the disease course.

The SUCLA2 gene is involved in the citric acid cycle and mtDNA synthesis [28]. In the citric acid cycle, SUCLA2 catalyzes the reversible formation of succinate and ATP from succinyl-CoA and ADP. This protein also interacts with nucleoside diphosphate kinase, which is involved in mtDNA synthesis [28]. Recessive SUCLA2 mutation causes mtDNA depletion syndrome, which could cause mild methylmalonic aciduria, recurrent vomiting, hypotonia, dehydration, respiratory distress, neonatal encephalopathy, and progressive lethargy [16]. Peripheral neuropathy could also be observed, as described for Patient 4. We identified two heterozygous variants in SUCLA2 from Patient 4: frame shift (c.1300delG) and splice site (c.664-1G > A); the latter was found to produce a protein that is three amino acids smaller than normal (p.L222_Q224del). The c.1300delG variant, located close to the 3 '-terminal of SUCLA2, is likely to produce a truncated protein (Fig. 11). Taken together with the segregation analysis, we classified these bi-allelic variants as pathogenic/ probably pathogenic.

Peripheral nerves have long axons wrapped in myelin lamellae provided by Schwann cells and are highly dependent on energy metabolism, ATP synthesis might eventually be influenced by any abnormalities in energy production and 
Table 2 Genetic pathophysiology, phenotype, inheritance pattern, and neuropathy type of the mitochondrial-related nuclear genes described in this report (upper table) and previously reported genes (lower table)

\begin{tabular}{|c|c|c|c|c|}
\hline Gene & Pathophysiology & Phenotype & Inheritance & Neuropathy type \\
\hline$P D H B$ & Pyruvate dehydrogenase complex & $\begin{array}{l}\text { Pyruvate dehydrogenase E1-beta defi- } \\
\text { ciency }\end{array}$ & $\mathrm{AR}$ & Sensory-motor axonal \\
\hline MTPAP & mtDNA maintenance and repair & $\begin{array}{l}\text { SPAX4 } \\
\text { Cellular radiosensitivity }\end{array}$ & AR & Sensory-motor axonal \\
\hline$H A D H B$ & $\begin{array}{l}\text { Mitochondrial energy production (beta- } \\
\text { oxidation) }\end{array}$ & Trifunctional protein deficiency & $\mathrm{AR}$ & Sensory-motor axonal \\
\hline SUCLA2 & $\begin{array}{l}\text { Mitochondrial energy production (tricar- } \\
\text { boxylic acid cycle), mtDNA synthesis }\end{array}$ & Mitochondrial DNA depletion syndrome 5 & $\mathrm{AR}$ & Sensory-motor axonal \\
\hline MFN2 & Mitochondrial dynamics (fusion) & CMT2A2, HMSN6 (CMT6A) & $\mathrm{AR}$ and $\mathrm{AD}$ & Sensory-motor axonal \\
\hline OPAl & Mitochondrial dynamics (fusion) & $\begin{array}{l}\text { Optic Atrophy I, Mitochondrial DNA } \\
\text { depletion syndrome }\end{array}$ & $\mathrm{AD}$ & Sensory-motor axonal \\
\hline GDAP1 & Mitochondrial dynamics (fission) & $\begin{array}{l}\text { CMT4A, CMT2K, CMTRIA, CMT with } \\
\text { vocal cord paresis }\end{array}$ & $\mathrm{AR}$ and $\mathrm{AD}$ & $\begin{array}{l}\text { Sensory-motor axonal (with or without } \\
\text { secondary demyelinating changes) }\end{array}$ \\
\hline$S L C 25 A 46$ & Mitochondrial dynamics (fission) & HMSN6B (CMT6B) & $\mathrm{AR}$ & Motor or sensory-motor axonal \\
\hline MYH14 & Mitochondrial dynamics (fission) & $\begin{array}{l}\text { Peripheral neuropathy, myopathy, hoarse- } \\
\text { ness, and hearing loss } \\
\text { Deafness, autosomal dominant 4A }\end{array}$ & $\mathrm{AD}$ & $\begin{array}{l}\text { Motor axonal } \\
\text { (with or without sensory demyelinating } \\
\text { changes) }\end{array}$ \\
\hline$M F F$ & Mitochondrial dynamics (fission) & $\begin{array}{l}\text { Encephalopathy due to defective mito- } \\
\text { chondrial and peroxisomal fission } 2\end{array}$ & $\mathrm{AR}$ & Motor demyelinating or mixed \\
\hline DHTKD1 & $\begin{array}{l}\text { Mitochondrial energy production (tricar- } \\
\text { boxylic acid cycle) }\end{array}$ & CMT2Q & $\mathrm{AD}$ & Sensory-motor axonal \\
\hline$H K 1$ & $\begin{array}{l}\text { Mitochondrial energy production (glyco- } \\
\text { lytic system) }\end{array}$ & CMT4G & $\mathrm{AR}$ & Sensory-motor demyelinating \\
\hline COX6A1 & $\begin{array}{l}\text { Mitochondrial respiratory chain (complex } \\
\text { IV) }\end{array}$ & CMTRID & $\mathrm{AR}$ & Sensory-motor axonal or mixed \\
\hline SURF1 & $\begin{array}{l}\text { Mitochondrial respiratory chain (complex } \\
\text { IV) }\end{array}$ & CMT4K, Leigh syndrome & $\mathrm{AR}$ & Sensory-motor demyelinating \\
\hline AIFMI & $\begin{array}{l}\text { Oxidative phosphorylation and redox } \\
\text { control in healthy cells }\end{array}$ & $\begin{array}{l}\text { CMTX4 (Cowchock syndrome) } \\
\text { Combined oxidative phosphorylation } \\
\text { deficiency }\end{array}$ & XLR & Sensory-motor axonal \\
\hline$P D K 3$ & Pyruvate dehydrogenase complex & СMTX6 & XLD & $\begin{array}{l}\text { Sensory-motor axonal (with or without } \\
\text { secondary demyelinating changes) }\end{array}$ \\
\hline C12orf65 & $\begin{array}{l}\text { Mitochondrial energy production (oxida- } \\
\text { tive phosphorylation), Mitochondrial } \\
\text { translation }\end{array}$ & $\begin{array}{l}\text { Combined oxidative phosphorylation } \\
\quad \text { deficiency } 7 \\
\text { SPG55, CMT6 }\end{array}$ & $\mathrm{AR}$ & Sensory-motor axonal \\
\hline POLG1 & mtDNA replication and maintenance & $\begin{array}{l}\text { Childhood MCHS, Alpers syndrome } \\
\text { ANS disorders, MEMSA, MNGIE-like, } \\
\text { SANDO } \\
\text { autosomal recessive and dominant PEO }\end{array}$ & $\mathrm{AR}$ and $\mathrm{AD}$ & $\begin{array}{l}\text { Sensory axonal; hypomyelinating when } \\
\text { early onset }\end{array}$ \\
\hline $\begin{array}{l}\text { C10orf2 } \\
\text { (Twinkle) }\end{array}$ & mtDNA replication and maintenance & $\begin{array}{l}\text { ANS disorders } \\
\text { Mitochondrial DNA Depletion Syndrome, } \\
\text { PEO }\end{array}$ & $\mathrm{AR}$ and $\mathrm{AD}$ & Usually sensory axonal \\
\hline TYMP & mtDNA replication and maintenance & $\begin{array}{l}\text { Mitochondrial DNA Depletion Syndrome, } \\
\text { MNGIE }\end{array}$ & $\mathrm{AR}$ & Sensory-motor demyelinating \\
\hline$R R M 2 B$ & mtDNA replication and maintenance & $\begin{array}{l}\text { Mitochondrial DNA Depletion Syndrome, } \\
\text { MNGIE-like, PEO }\end{array}$ & $\mathrm{AR}$ and $\mathrm{AD}$ & Sensory-motor demyelinating \\
\hline MPV17 & mtDNA maintenance & $\begin{array}{l}\text { Mitochondrial DNA Depletion Syndrome } \\
\text { Navajo neurohepatopathy }\end{array}$ & $\mathrm{AR}$ & Sensory-motor axonal or demyelinating \\
\hline SLC25A19 & mtDNA replication and maintenance & $\begin{array}{l}\text { Bilateral striatal degeneration and progres- } \\
\text { sive polyneuropathy }\end{array}$ & AR & Motor or sensory-motor axonal \\
\hline COA7 & $\begin{array}{l}\text { Assembling mitochondrial respiratory } \\
\text { chain complexes }\end{array}$ & $\begin{array}{l}\text { Spinocerebellar ataxia, autosomal reces- } \\
\text { sive, with axonal neuropathy }\end{array}$ & $\mathrm{AR}$ & Sensory-motor axonal \\
\hline
\end{tabular}

$A D$ autosomal dominant, ANS ataxia neuropathy spectrum, AR autosomal recessive, CMT Charcot-Marie-Tooth disease, CMTRIA CharcotMarie-Tooth disease, recessive intermediate A, CMTRID Charcot-Marie-Tooth disease, recessive intermediate D, HMSN hereditary motor and sensory neuropathy, MCHS myocerebrohepatopathy spectrum disorders, MEMSA myoclonus epilepsy myopathy sensory ataxia, MNGIE mitochondrial neurogastrointestinal encephalomyopathy, mtDNA mitochondrial DNA, PEO progressive external ophthalmoplegia, SANDO sensory ataxic neuropathy with dysarthria and ophthalmoparesis, SPAX4 spastic ataxia autosomal recessive Type 4, SPG55 spastic paraplegia 55, XLD X-linked dominant, XLR X-linked recessive 
depletion of mitochondria, leading to peripheral neuropathy. Moreover, various mitochondrial dysfunctions, such as dysfunctions in mitochondrial energy production or PDC, or assembling mitochondrial respiratory chain complex have been reported to cause CMT (Table 2) [2, 29-35]. Pathological mechanisms of each gene remain unclear, because peripheral nerves have long axons wrapped in myelin lamellae provided by Schwann cells and are highly dependent on energy metabolism; however, ATP synthesis might eventually be influenced by any abnormalities in energy production and depletion of mitochondria, leading to peripheral neuropathy (Fig. 5). As observed in patients with bi-allelic variants in $P D H B$ and SUCLA2, in mitochondrial disorders, multisystem manifestation representative of central nervous system involvement is a common feature suggestive of clinical diagnosis. Conversely, like MTPAP and $H A D H B$, these genes could hardly result in central nervous system abnormalities; thus, more attention should be paid to clinical assessments, particularly for certain symptoms that transiently emerged in their disease course and naturally disappeared with age. Moreover, because of the clinical diversity of these patients, peripheral neuropathy has always been recognized as part of the mitochondrial disorder rather than of CMT. Heterogeneous phenotypes of both mitochondrial disorders and CMT make the clinical diagnosis of either difficult. However, the development of diagnostic genetics has facilitated diagnoses made on a genetic basis.

In this study of a large Japanese cohort of patients with clinically suspected pure or complex hereditary peripheral neuropathy, we identified novel likely pathogenic/pathogenic
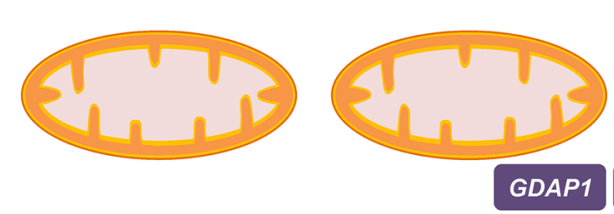

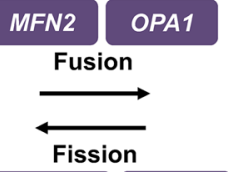

SLC25A46

\section{MFF}

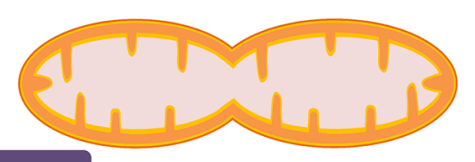

MYH14

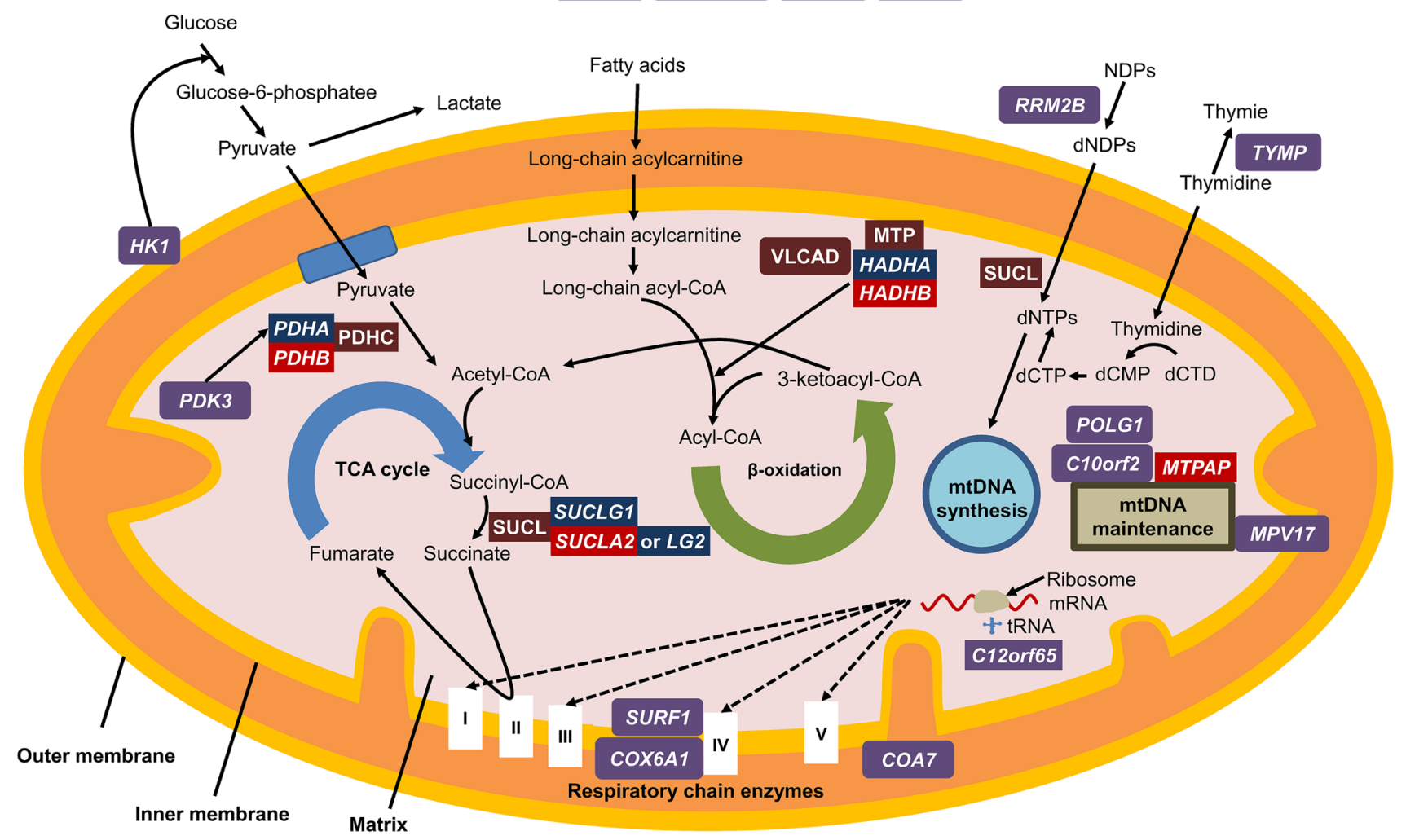

Fig. 5 Overview of the mechanisms underlying the main mitochondrial-related genes causing peripheral neuropathy and genes described in this report. Genes edged in purple are the main mitochondrial-related genes and those edged in red are the genes described in this report. PDHC comprises two alpha subunits $(P D H A)$ and two beta subunits $(P D H B)$. MTP comprises alpha subunits $(H A D H A)$ and beta subunits $(H A D H B)$. SUCL comprises an alpha subunit encoded by SUCLGI and a beta subunit encoded by either SUCLA2 or SUCLG2. CoA coenzyme A, dCMP deoxycytosine monophosphate, $d C T D$ deoxycytidine, $d C T P$ deoxycytosine triphosphate, $d N D P s$ deoxynucleoside diphosphates, $m t D N A$ mitochondrial DNA, MTP mitochondrial trifunctional protein, NDPs nucleoside diphosphates, $P D H C$ pyruvate dehydrogenase complex, SUCL succinyl-CoA ligase, TCA tricarboxylic acid, $V L C A D$ very-long-chain acyl-CoA dehydrogenase. 
variants in four mitochondrial-related nuclear genes. Mitochondrial abnormalities should be considered as a differential diagnosis in cases of axonopathy with suggestive symptoms or other unexplainable multisystem manifestations. Considering the limited number of gene panels targeted in our study, the discovery of more mitochondrial-related nuclear genes leading to mitochondrial-related neuropathy is highly likely. Regarding treatment, early diagnosis would provide more effective and prompt therapy strategies and medicines for the improvement of mitochondrial function might one day be a common target for mitochondrial neuropathy.

Supplementary Information The online version contains supplementary material available at https://doi.org/10.1007/s00415-022-11026-w.

Acknowledgements We sincerely thank Dr. Seiji Yamaguchi, Department of Pediatrics, Kobe University School of Medicine, for the measurement of the serum acylcarnitine in Patient 3; Ms. Tomoko Ohnishi and Aya Ebina of our department for their excellent technical assistance; and Enago (www.enago.jp) for providing the English-language editing of this report.

Funding We appreciate the Joint Research Laboratory, at the Kagoshima University Graduate School of Medicine and Dental Sciences, for the use of their facilities. This study was supported in part by grants from the Nervous and Mental Disorders and Research Committee for Charcot-Marie-Tooth Disease (Grant Number 17929553), Neuropathy, Ataxic Disease (201610002B), and Applying Health and Technology (201331010B) of the Ministry of Health, Welfare, and Labor, Japan; by the Research Program for Conquering Intractable Disease of the Japan Agency for Medical Research and Development (AMED) (201442014A, 201442071A), KAKENHI Kiban Bippan 18H02742, 21H02842; in part by JSPS KAKENHI Grant Number 26461275. This study was also supported in part by the Practical Research Project for Rare/Intractable Diseases from the Japan Agency for Medical Research and Development, AMED (JP21ek0109468, JP19ek0109273) and in part by Intramural Research Grant $(2-5,29-4)$ for Neurological and Psychiatric Disorders of NCNP.

Data availability statement Data are available on request from the authors.

\section{Declarations}

Conflict of interest The authors have no conflicts of interest to declare.

Open Access This article is licensed under a Creative Commons Attribution 4.0 International License, which permits use, sharing, adaptation, distribution and reproduction in any medium or format, as long as you give appropriate credit to the original author(s) and the source, provide a link to the Creative Commons licence, and indicate if changes were made. The images or other third party material in this article are included in the article's Creative Commons licence, unless indicated otherwise in a credit line to the material. If material is not included in the article's Creative Commons licence and your intended use is not permitted by statutory regulation or exceeds the permitted use, you will need to obtain permission directly from the copyright holder. To view a copy of this licence, visit http://creativecommons.org/licenses/by/4.0/.

\section{References}

1. Pipis M, Rossor AM, Laura M, Reilly MM (2019) Next-generation sequencing in Charcot-Marie-Tooth disease: opportunities and challenges. Nat Rev Neurol 15:644-656. https://doi.org/10.1038/ s41582-019-0254-5

2. Pareyson D, Piscosquito G, Moroni I, Salsano E, Zeviani M (2013) Peripheral neuropathy in mitochondrial disorders. Lancet Neurol 12:1011-1024. https://doi.org/10.1016/S1474-4422(13) 70158-3

3. Luigetti M, Sauchelli D, Primiano G, Cuccagna C, Bernardo D, Lo Monaco M, Servidei S (2016) Peripheral neuropathy is a common manifestation of mitochondrial diseases: a single-centre experience. Eur J Neurol 23:1020-1027. https://doi.org/10.1111/ene. 12954

4. Rath S, Sharma R, Gupta R, et al. (2021) MitoCarta3.0: An updated inventory of the mitochondrial proteome, now with suborganelle localization and pathway annotations. Nucleic Acids Res 49:D1541-D1547. https://doi.org/10.1093/nar/gkaa1011

5. Koopman WJ, Willems PH, Smeitink JA (2012) Monogenic mitochondrial disorders. N Engl J Med 366:1132-1141

6. Hashiguchi A, Higuchi Y, Nomura M et al (2014) Neurofilament light mutation causes hereditary motor and sensory neuropathy with pyramidal signs. J Peripher Nerv Syst 19:311-316. https:// doi.org/10.1111/jns. 12102

7. Maeda K, Idehara R, Hashiguchi A, Takashima H (2014) A family with distal hereditary motor neuropathy and a K141Q mutation of small heat shock protein HSPB1. Intern Med 53:1655-1658. https://doi.org/10.2169/internalmedicine.53.2843

8. Li H, Durbin R (2009) Fast and accurate short read alignment with Burrows-Wheeler transform. Bioinformatics 25:1754-1760. https://doi.org/10.1093/bioinformatics/btp324

9. Li H, Handsaker B, Wysoker A et al (2009) The Sequence Alignment/Map format and SAMtools. Bioinformatics 25:2078-2079. https://doi.org/10.1093/bioinformatics/btp352

10. Richards S, Aziz N, Bale S et al (2015) Standards and guidelines for the interpretation of sequence variants: a joint consensus recommendation of the American College of Medical Genetics and Genomics and the Association for Molecular Pathology. Genet Med 17:405-424. https://doi.org/10.1038/gim.2015.30

11. Murayama K, Nagasaka H, Tsuruoka T et al (2009) Intractable secretory diarrhea in a Japanese boy with mitochondrial respiratory chain complex I deficiency. Eur J Pediatr 168:297-302. https://doi.org/10.1007/s00431-008-0753-7

12. Yamamoto Y, Matsui N, Hiramatsu Y et al (2017) Mitochondrial trifunctional protein deficiency: an adult patient with similar progress to Charcot-Marie-Tooth disease. Rinsho Shinkeigaku 57:82-87. https://doi.org/10.5692/clinicalneurol.cn-000976

13. Fumihito N, Mioko M, Tomohiro K et al (2020) A rare case of SUCLA2-related mitochondrial DNA depletion syndrome. No To Hattatsu 52:318-322. https://doi.org/10.11251/ojjscn.52.318

14. Okajima K, Korotchkina LG, Prasad C et al (2008) Mutations of the E1beta subunit gene (PDHB) in four families with pyruvate dehydrogenase deficiency. Mol Genet Metab 93:371-380. https:// doi.org/10.1016/j.ymgme.2007.10.135

15. Crosby AH, Patel H, Chioza BA et al (2010) Defective mitochondrial mRNA maturation is associated with spastic ataxia. Am J Hum Genet 87:655-660. https://doi.org/10.1016/j.ajhg.2010.09. 013

16. Carrozzo R, Dionisi-Vici C, Steuerwald U et al (2007) SUCLA2 mutations are associated with mild methylmalonic aciduria, Leigh-like encephalomyopathy, dystonia and deafness. Brain 130:862-874. https://doi.org/10.1093/brain/awl389

17. Hong YB, Lee JH, Park JM et al (2013) A compound heterozygous mutation in HADHB gene causes an axonal Charcot-Marie-Tooth 
disease. BMC Med Genet 14:125. https://doi.org/10.1186/ 1471-2350-14-125

18. Lu Y, Wu R, Meng L et al (2018) HADHB mutations cause infantile-onset axonal Charcot-Marie-Tooth disease: a report of two cases. Clin Neuropathol 37:232-238. https://doi.org/10.5414/ NP301097

19. Dung VM, Suong DNA, Okamaoto $Y$ et al (2018) Neuron-specific knockdown of Drosophila PDHB induces reduction of lifespan, deficient locomotive ability, abnormal morphology of motor neuron terminals and photoreceptor axon targeting. Exp Cell Res 366:92-102. https://doi.org/10.1016/j.yexcr.2018.02.035

20. Li J, Suda K, Ueoka I et al (2019) Neuron-specific knockdown of Drosophila HADHB induces a shortened lifespan, deficient locomotive ability, abnormal motor neuron terminal morphology and learning disability. Exp Cell Res 379:150-158. https://doi. org/10.1016/j.yexcr.2019.03.040

21. DeBrosse SD, Okajima K, Zhang S et al (2012) Spectrum of neurological and survival outcomes in pyruvate dehydrogenase complex (PDC) deficiency: lack of correlation with genotype. Mol Genet Metab 107:394-402. https://doi.org/10.1016/j.ymgme. 2012.09.001

22. Sedel F, Challe G, Mayer JM, Boutron A, Fontaine B, Saudubray JM, Brivet M (2008) Thiamine responsive pyruvate dehydrogenase deficiency in an adult with peripheral neuropathy and optic neuropathy. J Neurol Neurosurg Psychiatry 79:846-847. https:// doi.org/10.1136/jnnp.2007.136630

23. Martin NT, Nakamura K, Paila U et al (2014) Homozygous mutation of MTPAP causes cellular radiosensitivity and persistent DNA double-strand breaks. Cell Death Dis 5:e1130. https://doi. org/10.1038/cddis.2014.99

24. Coelho D, Suormala T, Stucki M et al (2008) Gene identification for the cblD defect of vitamin $\mathrm{B}_{12}$ metabolism. N Engl J Med 358:1454-1464. https://doi.org/10.1056/NEJMoa072200

25. Bailey LB, Gregory JF III (1999) Folate metabolism and requirements. J Nutr 129:779-782

26. Naiki M, Ochi N, Kato YS et al (2014) Mutations in $H A D H B$, which Encodes the $\beta$-Subunit of mitochondrial trifunctional Protein, Cause Infantile Onset Hypoparathyroidism and peripheral
Polyneuropathy. Am J Med Genet A 164A:1180-1187. https:// doi.org/10.1002/ajmg.a.36434

27. Spiekerkoetter U, Bennett MJ, Ben-Zeev B, Strauss AW, Tein I (2004) Peripheral neuropathy, episodic myoglobinuria, and respiratory failure in deficiency of the mitochondrial trifunctional protein. Muscle Nerve 29:66-72. https://doi.org/10.1002/mus. 10500

28. Elpeleg O, Miller C, Hershkovitz E et al (2005) Deficiency of the ADP-forming succinyl-CoA synthase activity is associated with encephalomyopathy and mitochondrial DNA depletion. Am J Hum Genet 76:1081-1086. https://doi.org/10.1086/430843

29. Copeland WC (2008) Inherited mitochondrial diseases of DNA replication. Annu Rev Med 59:131-146. https://doi.org/10.1146/ annurev.med.59.053006.104646

30. Almutawa W, Smith C, Sabouny R et al (2019) The R941L mutation in MYH14 disrupts mitochondrial fission and associates with peripheral neuropathy. EBioMedicine 45:379-392. https://doi.org/ 10.1016/j.ebiom.2019.06.018

31. Koch J, Feichtinger RG, Freisinger P et al (2016) Disturbed mitochondrial and peroxisomal dynamics due to loss of MFF causes Leigh-like encephalopathy, optic atrophy and peripheral neuropathy. J Med Genet 53:270-278. https://doi.org/10.1136/jmedg enet-2015-103500

32. Abrams AJ, Hufnagel RB, Rebelo A et al (2015) Mutations in SLC25A46, encoding a UGO1-like protein, cause an optic atrophy spectrum disorder. Nat Genet 47:926-932. https://doi.org/10. 1038/ng.3354

33. Tucci A, Liu YT, Preza E et al (2014) Novel C12orf65 mutations in patients with axonal neuropathy and optic atrophy. J Neurol Neurosurg Psychiatry 85:486-492. https://doi.org/10.1136/ jnnp-2013-306387

34. Tamiya G, Makino S, Hayashi M et al (2014) A mutation of COX6A1 causes a recessive axonal or mixed form of CharcotMarie-Tooth disease. Am J Hum Genet 95:294-300. https://doi. org/10.1016/j.ajhg.2014.07.013

35. Higuchi Y, Okunushi R, Hara T et al (2018) Mutations in COA7 cause spinocerebellar ataxia with axonal neuropathy. Brain 141:1622-1636. https://doi.org/10.1093/brain/awy104 